\title{
Sofrimento psíquico e trabalho docente - implicações na detecção de problemas de comportamento em alunos
}

\section{Psychological distress and teaching - implications for the detection of problem behavior in students}

\section{Gabriela Franco Dias Lyra*}

Centro Latino Americano de Estudos de Violência e Saúde Jorge Careli - CLAVES/ FIOCRUZ, Rio de Janeiro, Rio de Janeiro, Brasil

\section{Simone Gonçalves de Assis**}

Centro Latino Americano de Estudos de Violência e Saúde Jorge Careli - CLAVES/ FIOCRUZ, Rio de Janeiro, Rio de Janeiro, Brasil

\section{Kathie Njaine***}

Centro Latino Americano de Estudos de Violência e Saúde Jorge Careli - CLAVES/ FIOCRUZ, Rio de Janeiro, Rio de Janeiro, Brasil

\section{Thiago de Oliveira Pires****}

Centro Latino Americano de Estudos de Violência e Saúde Jorge Careli - CLAVES/ FIOCRUZ, Rio de Janeiro, Rio de Janeiro, Brasil

\begin{abstract}
RESUMO
O presente artigo investiga a opinião de professores do ensino fundamental com e sem sofrimento psíquico - sobre os problemas de comportamento dos alunos e sobre a forma de lidar com esses problemas. Em 2006, 139 professores responderam um questionário autoaplicado a fim de avaliar algumas características do trabalho e a presença de sofrimento psíquico através da escala Self Reported Questionnaire (SRQ-20). Neste mesmo ano, estes profissionais avaliaram a presença de problemas de comportamento em 358 alunos, através da escala Teacher's Report Form (TRF). Em 2009, 10 Professoras da mesma amostra foram entrevistadas para compreender melhor sobre sua saúde mental e seu trabalho com os alunos. Resultados evidenciam diferenças significativas entre professores com e sem sofrimento psíquico no que tange à forma de avaliar e lidar com os problemas de comportamento dos alunos. A presença de sofrimento psíquico contribui para uma visão mais negativa do trabalho docente.

Palavras-chaves: Sofrimento Psíquico, Trabalho Docente, Problemas de Comportamento
\end{abstract}

\section{ABSTRACT}

This article aims to investigate the opinion of elementary school teachers with and without psychological distress - on the behavior's problems of the students and how to deal with these problems. In 2006, 139 teachers 
answered a questionnaire in order to evaluate some professional characteristics and the presence of psychological distress (Self Reported Questionnaire, SRQ-20). These professionals have also evaluated the presence of behavior problems in 358 students, through the scale Teacher's Report Form (TRF). In 2009, 10 teachers from the same sample were interviewed ( 5 teachers with signs of distress and 5 with no such signs). The results show significant differences between the two groups in regard to how to assess and deal with the problems of student behavior. Furthermore, it appears that the presence of psychological distress contributes to a more negative view of teaching.

Key words: Psychological Distress, Teaching, Behavior Problems

\section{Introdução}

A categoria de profissionais da educação tem sido objeto de estudos, sobretudo no que diz respeito às condições laborais e suas repercussões sobre a saúde dos trabalhadores (GASPARINI; BARRETO; ASSUNÇÃO, 2005; ARAÚJO; SILVANY NETO, 1998; MARIANO ; MUNIZ , 2006). Como afirma Dejours (1992), a atividade profissional favorece o bem-estar quando se apresenta como fonte de prazer e satisfação para a realização das atividades que são conferidas ao trabalhador. Paradoxalmente, o trabalho pode ser fonte de sofrimento à medida que o trabalhador se confronta com as estruturas da organização que lhe são impostas e tão pouco consegue modificá-las.

As condições de trabalho e saúde do Professor constituem-se um problema crítico para a educação brasileira. Observa-se que no decorrer dos anos, a atividade docente - que antes ocupava um lugar de destaque no cenário das profissões - passou por um processo de precarização, desencadeado pelo pouco investimento e reconhecimento da profissão no campo das políticas públicas educacionais. Investigações nacionais com Professores de escolas públicas e particulares demonstram a insatisfação desses profissionais com a carreira docente e o quanto a profissão tem se desvalorizado (RISTUM, 2001; JUNQUEIRA; MULS, 1997; DELCOR; ARAÚJ O; REIS; PORTO; CARVALHO; SILVA, 2004).

Com relação à saúde dos professores, estudos vêm sugerindo a íntima relação entre condições de trabalho e sofrimento psíquico (NEVES; SILVA, 2006; GASPARINI; BARRETO; ASSUNÇÃO, 2006; PORTO; CARVALHO; OLIVEI RA; NETO; ARAÚJ O; REIS; DELCOR, 2006). Este sofrimento caracteriza-se por um mal-estar inespecífico, com repercussões fisiológicas e psicológicas que podem acarretar limitações severas no dia a dia, podendo se transformar em doença pela sua intensidade e cronicidade (COUTINHO, 1995). Por seu caráter transitório, esses problemas não necessariamente originam a 
procura imediata por intervenção médica, mas podem interferir nas relações e observações do indivíduo no seu cotidiano de trabalho.

Por se diferenciar das demais profissões devido ao investimento afetivo e emocional estabelecido na execução do seu trabalho, os professores são particularmente privilegiados na identificação das dificuldades apresentadas pelos alunos. Considerando a sala de aula um espaço de manifestação dessas dificuldades, o longo tempo de convivência com o aluno pode contribuir para o reconhecimento de problemas de comportamento e, consequentemente, uma intervenção através de encaminhamentos a profissionais especializados, quando necessário. Outro fator é que sinais que indicam problemas de comportamento podem ser mais visíveis em crianças quando confrontadas com seus pares.

Os problemas de comportamento em crianças são muito pouco estudados na realidade nacional. Estima-se que entre $10-20 \%$ das crianças apresentam algum problema de saúde mental, estando estes entre as cinco principais causas de doença acima de cinco anos de idade (BIRD, 1996; MURRAY, 1996). De uma maneira geral, representam déficits ou excedentes comportamentais que prejudicam a interação da criança com os pares e adultos de sua convivência (Silva, 2000). São frequentemente divididos em problemas que se externalizam (sintomas de comportamento de violação de regras e agressividade, assim como os problemas de conduta) e problemas que se internalizam (sintomas de depressão, ansiedade e queixas somáticas) (BEE, 1996).

Um estudo no Brasil mostrou resultados próximos aos de países desenvolvidos. Investigação com 1251 crianças escolares de 7-14 anos, em Taubaté/São Paulo, encontrou uma prevalência de problemas de comportamento de $12,5 \%$. Considerando os tipos de problemas, verificou-se que a maior frequência ocorreu no grupo de problemas de conduta, com estimativas em torno de $7 \%$. Em segundo, prevaleceram os problemas de ansiedade, cuja ocorrência foi de $5,2 \%$. Os problemas de déficit de atenção/hiperatividade representaram $1,5 \%$ das crianças estudadas (FLEITLICH-BILYK; GOODMAN, 2004).

Visando contribuir com o conhecimento sobre o tema, o presente artigo investiga a opinião de professores do ensino fundamental com e sem a presença de sofrimento psíquico- sobre os problemas de comportamento dos alunos e sobre a forma como eles próprios lidam com crianças com essas dificuldades. Embora a visão do Professor seja frequentemente útil em pesquisas para avaliar problemas de comportamento em crianças, pouco é conhecido sobre os fatores que podem influenciar seus relatos. Busca-se também neste estudo investigar se as condições de saúde e trabalho do Professor afetam a identificação de problemas e/ou se são afetadas por esses problemas infantis. 


\section{Metodologia}

O presente artigo originou-se de uma pesquisa longitudinal com 500 crianças, iniciada em 2005, que buscou conhecer a magnitude dos problemas de comportamento dos alunos matriculados em escolas municipais da rede de ensino pública do município de São Gonçalo/Rio de Janeiro caracterizada por possuir população com baixo poder aquisitivo e pela precariedade de serviços públicos (CIDE, DATASUS). As crianças foram selecionadas por amostragem por conglomerado simples em estágios: escolas, turmas de $1 \underline{a}$ série do ensino fundamental e alunos.

Os dados quantitativos analisados neste artigo referem-se ao acompanhamento de 358 crianças aferidas por 139 Professoras (todas do sexo feminino), em 83 escolas em que os alunos estudavam no ano de 2006, tendo em vista as perdas ocorridas no decorrer da pesquisa. Nesta abordagem metodológica, introduzem-se informações dos Professores sobre os problemas de comportamento apresentados pela criança na escola nos últimos dois meses através do instrumento Teacher's Report Form - TRF (ACHENBACH; RESCORLA, 2001; BORDIN; MARI; CAEIRO, 1995). A escala possui 118 itens, sendo considerada a presença de problemas em nível clínico ou limítrofe quando a criança atinge o escore $T>=60$. A aplicação da TRF com escala similar respondida pelos responsáveis das crianças mostrou correlação significativa $(p<0,001)$ (Assis, 2007), tal como observado em outros estudos internacionais (FERDINAND; VAN DER ENDE; VERHULST, 2007; KOLKO; KAZDIN, 1993).

Ainda faz parte da abordagem quantitativa a aferição da presença de sofrimento psíquico (SP) em Professores avaliada também no ano de 2006 através do instrumento Self Reported Questionnaire - SRQ20 (HARDING, 1980; MARI; WILLIAMS, 1986); 8 itens respondidos positivamente dentre os 20 perguntados configura a presença de sofrimento psíquico. O recorte empírico de sofrimento psíquico feito pela SRQ-20 serve como instrumento de rastreio para estudos populacionais, não representando diagnóstico psiquiátrico. Restringese a um determinado número de sinais de sofrimento mental, distinguindo-se de certa forma de conceitos de teóricos como Dejours(1992), para os quais tal sofrimento é inerente ao processo de trabalho.

Algumas características do trabalho das educadoras foram ainda aferidas: condições de vida depois que começou a dar aula e de trabalho ao longo do tempo (melhorou, continua igual, piorou); o que faria se pudesse começar de novo a vida profissional (escolheria exatamente a mesma carreira, optaria pela mesma carreira desde 
que ela possibilitasse melhores condições de trabalho, optaria por uma atividade parecida fora da escola ou escolheria outra carreira completamente diferente); número de alunos por turma em que dá aulas; número de escolas em que dá aula por semana; hábito de sair de uma escola para trabalhar em outra escola imediatamente, sem descanso algum.

Os dados foram digitados e inseridos no programa Epidata versão 3.1 e a análise foi realizada através do programa Statistical Package for Social Sciences - SPSS, versão 15. Foram feitas frequências simples para descrever os dados, tabelas de contingência para evidenciar uma possível associação entre o sofrimento psíquico e algumas variáveis selecionadas. Nas análises de associação foram utilizados o Teste Exato de Independência e o teste Exato de Fisher (AGRESTI, 2002). Para variáveis contínuas foram utilizadas médias e desvios padrões. A comparação das amostras empregou o teste de MannWhitney. Foi definido nível de significância de 5\%.

Quanto à abordagem qualitativa, em 2009, foram realizadas 10 entrevistas a partir da mesma amostra de professores que participaram da pesquisa em 2006. Dentre elas cinco (5) Professoras foram escolhidas aleatoriamente dentre as que apresentavam os mais elevados escores de sofrimento psíquico (SRQ-20) em 2006, denominadas a seguir como "C/ SP"; b) e cinco (5) Professoras sem estes sintomas em 2006 (s/ SP). No momento da entrevista, em 2009, nem as Professoras e nem a entrevistadora sabiam do status de sofrimento psíquico apresentado em 2006. Após cada entrevista qualitativa aplicou-se novamente a escala SRQ 20 às Professoras, a fim de confirmar o status de sofrimento psíquico três anos após (2009). Na reaplicação da SRQ 20, todas as cinco (5) Professoras que não apresentaram SP em 2006, se mantiveram com boa saúde mental em 2009. Dentre as Professoras com SP, três (3) permaneceram com tal transtorno e duas (2) revelaram superação dos sentimentos de depressão, ansiedade e somatização (aferidos pela escala SRQ-20). Todavia, estas duas (2) Professoras que apresentaram SP em 2006 e não apresentaram o transtorno em 2009 se referiram espontaneamente durante a entrevista a sentimentos angustiantes e a dificuldades físicas vividas no magistério em anos anteriores a 2009. Todos os nomes apresentados no texto são fictícios. Os resultados distinguem os grupos de Professoras segundo a avaliação de SP realizada em 2006.

Para análise dos dados qualitativos, utilizou-se a análise de conteúdo proposta por Bardin (1979) na modalidade temática, originando os seguintes temas: avaliação dos alunos com problemas de comportamento; aspectos que contribuem para a presença de problemas de comportamento nos alunos; mecanismos utilizados para lidar com as crianças com problemas de comportamento; condições de trabalho docente; relações entre trabalho e saúde 
docente; relações entre problemas de comportamento dos alunos e condições de saúde e trabalho docente.

A teoria das representações sociais (J ODELET, 2001; RANGEL, 1993) auxilia a análise realizada, permitindo compreender o sentido que as Professoras atribuem aos problemas de comportamento e as formas como elas lidam com os mesmos em sala de aula.

O presente estudo foi aprovado pelo Comitê de Ética do Instituto Fernandes Figueira/FIOCRUZ.

\section{Resultados}

Como forma de ilustrar a percepção das Professoras sobre os alunos e a relação com a presença de sofrimento psíquico, verifica-se na tabela 1, as associações entre algumas características do processo educativo e a presença de sofrimento psíquico nas Professoras estudadas.

Observa-se que não houve associação entre a presença de sofrimento psíquico entre Professoras e: relação Professor-aluno, conflitos existentes e intervenções realizadas (por exemplo, encaminhamento para classe especial, programas especiais ou reforço escolar). No entanto, as Professoras c/SP apresentam uma visão diferenciada em relação àquelas S/SP ao identificarem com maior frequência que seus alunos se dedicam menos aos estudos, que aprendem menos e que são menos felizes comparados aos demais colegas. Também são mais negativas em relação à avaliação do desempenho dos alunos em história, geografia e ciências, se comparados com os colegas da mesma idade. 
Gabriela Franco Dias Lyra, Simone Gonçalves de Assis,

Kathie Njaine, Thiago de Oliveira Pires

Sofrimento psíquico e trabalho docente - implicações na detecção de problemas de comportamento em alunos

Tabela 1: Sofrimento psíquico e avaliação dos professores sobre os alunos

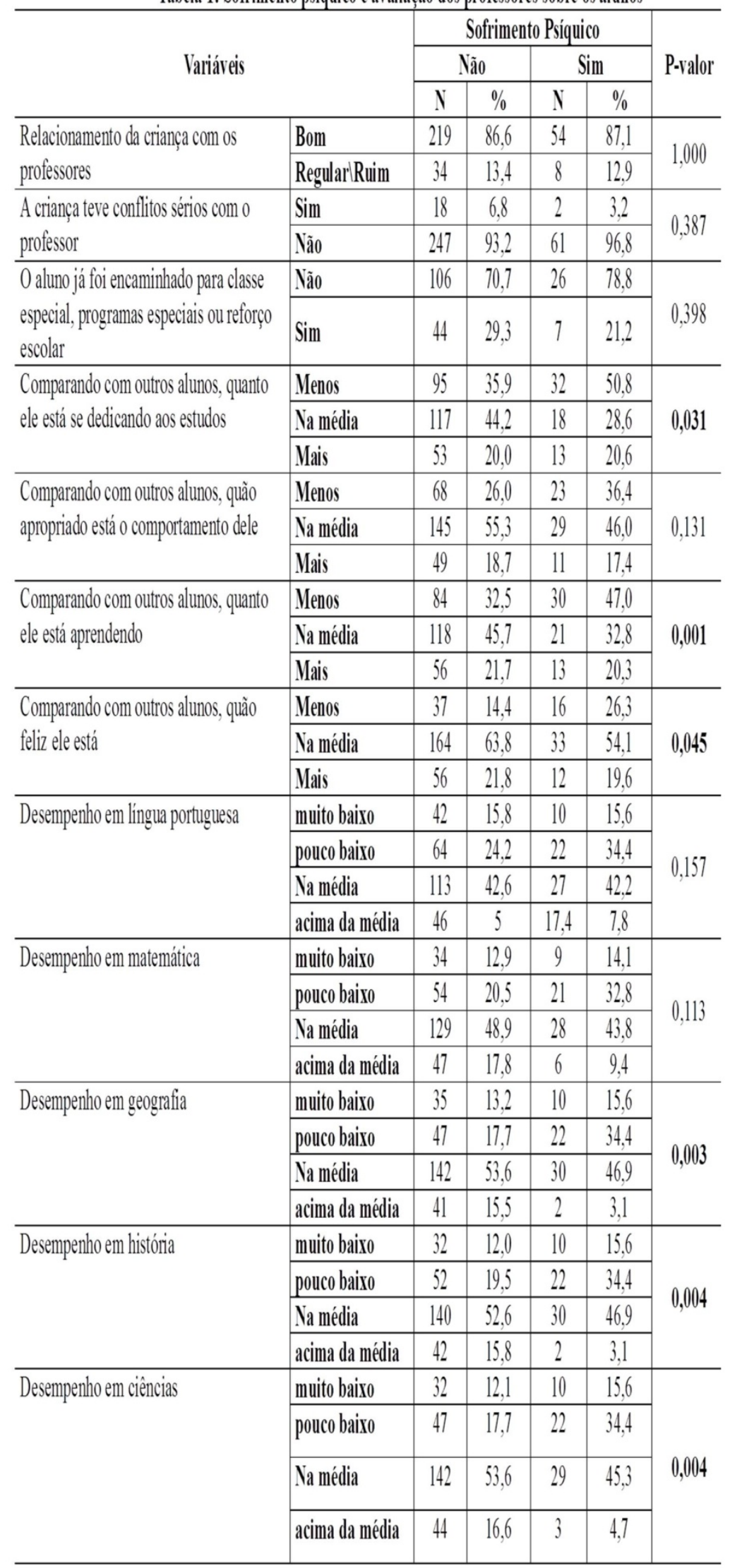




\section{Como as professoras avaliam os alunos com problemas de comportamento.}

Para se compreender melhor como as professoras avaliam os alunos com problemas de comportamento apresenta-se a prevalência com que as Professoras identificam dificuldades nos alunos: $12,6 \%$ de alunos com problemas externalizantes (comportamento agressivo e violação de regras), $10,8 \%$ problemas com a atenção (déficit de atenção e hiperatividade) e 9,1\% problemas internalizantes (ansiedade, depressão, queixas somáticas). professoras com SP identificam mais problemas internalizantes em seus alunos do que as sem SP (LYRA; ASSIS; NJ AINE; OLIVEIRA; PIRES,2009).

$\mathrm{Na}$ fala das professoras entrevistadas, os problemas de comportamento manifestados pelos alunos se baseiam, predominantemente, em características de comportamentos externalizantes, independente da presença ou ausência de sofrimento psíquico nessas profissionais. O comportamento de irritabilidade, agitação em sala de aula, dificuldade de se relacionar com o colega e agressividade são relatados pelas professoras como sendo características típicas de alunos com esses problemas. Estes resultados não são surpreendentes, uma vez que tais comportamentos são considerados os mais insatisfatórios em sala de aula, como ilustrado nas falas a seguir:

Eles são muito agitados, muito agressivos, palavrões são frequentes (...). Eles se tratam mal, não têm respeito, não se respeitam e não respeitam o colega [...] Distúrbio de comportamento mesmo que geram brigas, discussões. Se olhou, já é motivo de briga. Então a gente costuma dizer que eles estão à flor da pele (Marcela, c/ SP, 37 anos).

É muito difícil pra eles se relacionarem um com o outro. Eles são muito agressivos. [...] Não têm paciência um com o outro (Conceição, s/SP, 57 anos).

A identificação dos problemas internalizantes nos alunos é pouco realizada. Apenas as professoras que confirmam a presença de sofrimento psíquico identificam sinais desses problemas nos alunos, através da observação de aspectos como apatia em sala de aula.

Ou é uma apatia. Na outra escola essa semana, eu tenho um aluno super agitado, ele não para, é o tempo inteiro brigando, é o tempo todo discutindo em sala de aula. Um dia desses ele chegou, parecia que ele não estava na sala. Alguma coisa aconteceu. Ele de cabeça baixa, fez dever, um ano inteiro uma criança não faz nada, super agitada. Fez dever, sentou (Marcela, c/ SP, 37 anos). 
A gente sempre vê que por detrás daquele problema da criança, ou a criança é apática ou é ativa demais e exagera no comportamento na sala de aula (Gisela, c/ SP, 43 anos).

Verifica-se também que o grupo das professoras com sofrimento psíquico relata formas mais tênues de se perceber os problemas dos alunos, que não somente pela identificação de comportamentos extremos. Algumas dessas formas podem ser averiguadas na maneira como as professoras trabalham e avaliam os seus alunos. Para algumas dessas professoras, os trabalhos produzidos pelos alunos podem indicar elementos que facilitam apreender as dificuldades emocionais e comportamentais dos mesmos.

Através de desenhos, através de produção textual, quando você pega produção textual de uma criança, que tem algum problema, alguma dificuldade, a própria produção textual, ela já define muito pra você, o perfil psicológico de uma criança. [...] $E$ as cores também falam muito. Eu tenho um aluno e nós o estamos ajudando bastante. Ele só usa marrom, preto, roxo. Então é essa agressividade toda. Mas vem de um lar completamente destruído. O pai é alcoólatra, bate na mãe [...] Então, o mundo dele realmente é marrom, é roxo e preto. O mundo dele não pode ser rosa, azul, amarelinho (Rosana, c/ SP, 41 anos).

Esses aspectos fazem supor a existência de conexão afetiva e sensibilidade por parte dessas Professoras.

Quando ela colocou no papel a sua ação diária com a madrasta, aí eu pude observar o porquê. A mãe morreu com câncer, há um ano. [...] Eu não posso esperar dessa criança a mesma coisa de uma criança de um lar organizado e feliz. O próprio texto que ela fez, mostrou pra mim a tristeza de alma que ela está. Não sabe nem porque, mas quer agredir. É uma criança (Marcela c/ SP, 37 anos).

\section{5 o que contribui para o surgimento dos problemas de comportamento.}

Na visão das Professoras de ambos os grupos os fatores familiares são os que mais contribuem para o surgimento dos problemas de comportamento nas crianças. Das falas, destacam-se: falta de limites e orientação, ausência de atenção e carinho, questões sociais que envolvem as famílias (desemprego e pobreza). Em síntese, a responsabilidade recai sobre a falta de assistência dos pais, seja pelo desinteresse em prover a educação dos filhos, seja devido a problemas sociais. 
Verifica-se também que, em ambos os grupos, os comportamentos são vistos como reflexos da vida fora da escola. Dito de outra forma é como se a escola não contribuísse de modo algum para a presença desses comportamentos:

\footnotetext{
Então ela vai vir com todos esses vícios, pra dentro da sala de aula (Alba, c/ SP, 35 anos).

O que eles vivem, o que eles vêem, [...] acaba refletindo aqui na escola (Mônica, s/ SP, 32 anos).
}

Indagadas pelos pesquisadores sobre outros possíveis fatores que poderiam contribuir para os problemas de comportamento, como por exemplo, a comunidade e a escola, as professoras de ambos os grupos consideram a violência nas comunidades como um fator que contribui para o desencadeamento desses problemas. Entretanto, para a maioria, a escola não é considerada um espaço que pode potencializar o surgimento de problemas de comportamento. Apenas duas professoras sem sofrimento psíquico reconhecem a participação da escola através de aspectos como a falta de recursos e a dinâmica do espaço escolar, que, por ser um espaço com diversas pessoas convivendo ao mesmo tempo, torna-se agitado e acaba facilitando a agitação trazida pelo aluno. A afirmação unânime do grupo de professoras com sofrimento é que a escola não contribui para as dificuldades emocionais e comportamentais de seus alunos, reforçando uma visão linear da escola isolada do contexto social.

\section{Como as professoras lidam com as crianças com problemas de comportamento.}

As estratégias adotadas por professoras de ambos os grupos para lidar com alunos com problemas de comportamento baseiam-se na resolução dos conflitos com o próprio aluno. Conversar, brigar, conscientizar, chamar a atenção, ensinar a respeitar e ter uma postura rígida em sala de aula são estratégias relatadas para problemas que surgem em sala de aula, demonstrando determinação e flexibilidade na resolução de conflitos decorrentes desses comportamentos.

Professoras com SP predominam na referência a encaminhamentos dos alunos como alternativa viável para lidar com determinadas situações em sala de aula. Para elas, a ajuda de outras instâncias da escola, como a orientação pedagógica e a direção da escola, é essencial para o Professor trabalhar com os alunos que apresentam problemas: 
Quando ele apresenta constantemente esse comportamento inadequado, a gente pede auxílio praticamente pra escola inteira (Rosana, c/ SP, 41 anos).

Eu encaminho para direção, a direção tem uma advertência que eles assinam. Na terceira advertência, o responsável é chamado. Aí a gente conversa. Mas, sempre assim, encaminhando pra direção. Porque eu não posso tomar nenhuma atitude na sala de aula, nem por pra fora o aluno, até porque, eu não concordo com isso (Gisela, c/ SP, 43 anos).

Os encaminhamentos para setores especializados, tais como o serviço de psicologia, fonoaudiologia e neurologia são referidos como necessários e urgentes para muitos alunos que apresentam problemas em sala de aula. No entanto, esses encaminhamentos são muito dificultados pela falta de apoio dos responsáveis e pela ausência desses serviços no município, causando um transtorno para o Professor:

Encaminha, mas depende do responsável levar, o responsável trabalha fora, então uma série de problemas que prejudica o nosso trabalho em sala de aula (...) Você encaminha um aluno pra um psicólogo e o aluno é capaz de terminar o ensino fundamental todo e não conseguir a vaga. Nós precisamos de ajuda (Marcela c/ SP, 37 anos).

Em consonância com a fala acima, verifica-se que lidar com esses problemas e não contar com nenhum apoio desencadeia um processo de estresse ao Professor. Após relatar a dificuldade que tem para lidar com esses problemas, uma Professora refere não saber trabalhar com a sua própria agressividade nos momentos de tensão e, por isso, acaba por tratar o aluno de forma ríspida e severa em sala de aula:

Muitas vezes você acaba se tornando áspera, ríspida. Porque se vê numa situação que é constante dia a dia. Aí você chama a responsável, você fala com a coordenação, com a direção (Marcela, c/ SP, 37 anos).

A falta de preparo de alguns profissionais para lidar com os conflitos em sala de aula também pode contribuir significativamente para uma visão reducionista dos problemas dos alunos e desencadear atitudes autoritárias sem vislumbrar um caminho para a sua resolução. O depoimento abaixo ilustra a idéia do problema como único e exclusivo do aluno, reduzindo assim o leque de opções de enfrentamento:

Tento fazer assim, conscientizar. Eu recebi um aluno que é da outra sala, está na minha sala, por mau comportamento. Aí quando eu vejo que ele está muito agitado, eu chamo ele e converso: "Olha só. Você está aqui porque eu fui legal com 
você. Eu te dei uma oportunidade, a escola te deu uma oportunidade" (Alba, c/ SP, 35 anos).

Por outro lado, verifica-se nas falas das Professoras com sofrimento psíquico um grande sentimento de impotência perante os problemas de comportamento manifestados em sala de aula, aspecto que se agrava em função da precária formação do Professor para lidar com esses problemas.

O Professor ele não é preparado pra lidar com essas situações que nós estamos enfrentando. O quê que eu vou fazer? A quem eu vou recorrer pra ajudar? [...] São quatro horas assim, que a gente tem que fazer milagre. É como se diz por aí, tirar leite de pedra, não é nem água (Marcela, c/ SP, 37 anos).

O que contribui mais é a nossa, praticamente, impotência diante da situação, porque se a gente lida de uma maneira, aí vem a família, já vê de outra forma. Então, você não tem como interferir na família, não (Daniela, c/ SP, 35 anos).

\section{Condições de vida e trabalho e como o trabalho afeta a saúde das professoras.}

Um total de $21,8 \%$ das 139 professoras evidenciaram sofrimento psíquico (SP) em 2006.

A tabela 2 apresenta dados sobre as características do trabalho das Professoras. De uma forma geral, as Professoras relatam uma vida melhor após o ingresso no magistério. Todavia, mais Professoras com SP $(24,1 \%)$ referem que a vida piorou depois que iniciou a carreira de Professora ( $1 \%$ entre educadoras S/ SP; $p<.001$ ).

Quando questionadas sobre a possibilidade de começar de novo sua vida profissional, apenas $13,8 \%$ das Professoras com SP continuariam na mesma carreira $(39,2 \%$ das sem SP afirmaram que ficariam na mesma carreira, $p=0,002$ ).

Não houve associações estaticamente significativas entre SP e condição de trabalho do Professor ao longo do tempo, número de alunos por turma e de escolas em que dá aula por semana, trabalho em mais de uma escola sem descanso algum, tempo de trabalho como Professor e tempo que fica com os alunos.

Nas entrevistas, as professoras são unânimes em afirmar que as condições de trabalho que vivenciam são precárias, fundamentandose na ausência de recursos materiais e humanos, na difícil acessibilidade das escolas, no espaço limitado para se trabalhar, bem como na pouca valorização do professor, comparada ao trabalho desempenhado. A carga de trabalho e as condições salariais são aspectos também apontados com bastante ênfase. 
Muitas queixas relacionaram condições de trabalho à saúde do docente. Problemas respiratórios em virtude do uso do giz, mau uso da voz em virtude do barulho excessivo, estresse do dia a dia são citados como características que afetam a saúde do Professor. Ansiedade, dor, cansaço, estresse e nervosismo são alguns dos sintomas relacionados ao trabalho:

\begin{abstract}
Eu grito demais. Eu estou há dezoito anos, eu grito, eu tenho que desapartar briga. É como se eu vivesse assim num barril de pólvora enquanto eu estou aqui... Está me afetando muito, está me deixando ansiosa, porque, você não consegue resolver (Marcela, c/ SP, 37 anos).

A gente trabalha no meio de muito barulho. Estresse. Acho que meu caso é esse aí (Flávia S/ SP, 42 anos).

Eu fiquei hipertensa com o magistério (Rosana, C/ SP, 41 anos).
\end{abstract}

A baixa expectativa em relação à profissão e também a baixa autoestima são características que foram mais observadas no grupo das Professoras com SP. A sensação de um trabalho improdutivo, a alta carga de trabalho destinada ao Professor, o desprestígio, o sentimento de impotência e a frustração perante situações decorrentes das vidas dos alunos demonstram um processo de insatisfação e o consequente adoecimento dessas professoras.

Você vê que seu trabalho não é nada, você está ali para nada, porque não deixam você trabalhar. Eu tenho aluno de dezesseis anos na quarta série. Então eu me sinto super ansiosa, eu me sinto nervosa (Marcela c/SP, 37 anos).

Eu vejo tanta coisa triste, que não tem como sair daqui conforme você entrou... Então, quando eu vejo certos problemas dos meus alunos, eu me envolvo. Eu não quero, eu sou sincera, eu não quero, mas eu me envolvo (Rosana, c/ SP, 41 anos).

Que a gente fica estressada. Eu, por exemplo, trabalho de manhã, tarde e noite. Então é uma carga de trabalho muito grande (Gisela, c/ SP, 43 anos).

\title{
8 Problemas de comportamento dos alunos e condições de saúde e trabalho docente
}

Não houve consenso à pergunta se os problemas de comportamento dos alunos afetam de alguma forma a saúde e a qualidade do trabalho das Professoras. No grupo das Professoras sem SP, algumas consideram os problemas de comportamento dos alunos como um fator potencializador para os problemas de sua saúde. Aquelas que assim consideram, destacam o estresse e a preocupação resultantes 
do trato com os alunos como motivos que, de alguma forma, afetam a sua saúde.

No caso das Professoras com sofrimento psíquico, com exceção de uma, todas afirmam enfaticamente que os problemas de comportamento dos alunos afetam a qualidade do trabalho e a saúde do Professor. Foram relatadas a ansiedade, o nervosismo e a irritação em virtude dos problemas recorrentes em sala de aula e das preocupações em relação aos problemas dos alunos. Sentimentos de estarem sozinhas, sem apoio, e de cumprirem um papel que não é atribuição docente são destacados como fatores desencadeados por problemas comportamentais de alunos. O medo e falta de estímulo também são relatados como aspectos resultantes dos problemas de alunos e que afetam a qualidade de vida das Professoras:

\begin{abstract}
Afetam sim porque o comportamento faz com que eu fique irritada. E a irritação, ela prejudica a saúde (Rosana, c/SP, 41 anos).

Eu tive princípio de depressão, eu tive síndrome do pânico, porque era uma turma que, olha, eu não sei como não me mataram (...) (Daniela c/ SP, 35 anos).

Você quer controlar a turma, mas às vezes não dá pra controlar. Fico bastante nervosa às vezes até tenho batimentos acelerados do coração, até sinto isso (Gisela c/ SP, 43 anos).
\end{abstract}

\title{
9 Discussão
}

As representações das professoras sobre problemas de comportamento nos alunos indicam suas posições frente ao cotidiano e influenciam na construção das relações e das práticas pedagógicas na escola. De acordo com Coll e Miras (2001), as representações que docentes fazem de seus alunos interferem na dinâmica da sala de aula à medida que contribuem para interpretar o que os alunos fazem e reagir de forma diferente ante os progressos e dificuldades encontrados.

No processo de construção deste artigo, foi possível perceber como as Professoras apreendem os problemas de comportamento dos alunos e de que modo lidam com esses comportamentos no dia a dia. O que pensam sobre as condições de trabalho e quais os reflexos que a atividade docente tem sobre a saúde dos professores foram questões também abordadas, considerando que a atuação desses profissionais está articulada às diversas esferas da vida.

Nessas representações, observa-se uma relação íntima entre a presença de problemas de comportamentos e a questão da indisciplina em sala de aula (GARCIA, 2009). Essa associação contribui para uma visão dos problemas como algo que perturba o 
processo da aula, condutas inadequadas às normas estabelecidas e atitudes de rebeldia ou recusa que quebram regras e negam as orientações da escola, reduzindo assim, todo um leque de dificuldades emocionais e comportamentais à questão da indisciplina. Conforme Garcia (2009), isso pode ser em parte justificado, pois, ao elaborar um conjunto de expectativas sobre a disciplina em sala de aula, os professores tendem a emitir juízos sobre os alunos. Ou seja, cria-se um conjunto de expectativas em torno da disciplina e quando estas não são alcançadas o aluno é considerado "problemático". De uma forma geral, a identificação de problemas de comportamento em todas as falas analisadas assume esta característica, embora relacionem os contextos comunitários e familiares influenciando esse comportamento. O olhar do professor, neste caso, deixa em dúvida se há um verdadeiro reconhecimento dos problemas de comportamento dos alunos ou se, na ânsia de se alcançar um ambiente propício e favorável ao processo de ensino/aprendizagem, comportamentos tidos como insatisfatórios são considerados problemas de comportamento.

A visão das professoras sobre o que contribui para os problemas de comportamento dos alunos expressa um entendimento de que sua gênese está fundamentada no contexto familiar ou no aspecto individual do aluno. Desconsidera fatores associados à própria dificuldade do processo de escolarização, bem como outros fatores socioambientais. Assim, os problemas escolares são entendidos dentro de uma perspectiva de medicalização/psicologização (BOARINI; BORGES, 1998), atribuindo às Professoras posições mais estáticas acerca do problema e reforçando a retórica de culpabilização e exclusão em detrimento de mudanças institucionais que visem um ambiente mais participativo e democrático. Como afirma Silva (1999), dependendo da concepção e da direção que a escola assuma, esta poderá ser um local de busca e consolidação de direitos ou de reprodução de desigualdades.

Um estudo sobre a análise dos encaminhamentos de crianças com queixa escolar da rede municipal de ensino de Caxias do Sul (RS) em 2004 verificou um número excessivo de encaminhamentos ao setor de psicologia e alguns equívocos com relação à identificação de problemas de comportamento. Muitas queixas sobre falta de atenção e concentração estavam associadas ao rótulo de hiperatividade, ao passo que somente um caso foi diagnosticado por um médico neurologista como transtorno de déficit de atenção e hiperatividade TDAH (SCORTEGAGNA; LEVANDOWSKI, 2004).

A realização das entrevistas permitiu verificar que as condições de trabalho são desfavoráveis de múltiplas formas. A dificuldade de realizar as entrevistas devido à falta de espaço, ao receio do Professor deixar os alunos sozinhos em sala, ao barulho excessivo na escola e às inúmeras interrupções no decorrer da entrevista foram 
alguns eventos vivenciados pelos pesquisadores em pouco tempo, porém suficientes para entender um pouco as inquietudes do Professor da rede pública de São Gonçalo.

A presença de SP em cerca de 1 em cada 5 professoras observada na abordagem quantitativa é um fator relevante e significativo. Pode sinalizar uma maneira especial de avaliar os alunos e a falta de apoio obtida na escola, tal qual apontado nos resultados deste artigo. Todavia, não se pode afirmar causalidade, podendo-se apenas ater a associação entre este transtorno psíquico e visão das educadoras sobre seus alunos e suas condições de trabalho.

No tocante aos problemas internalizantes, observa-se que as entrevistas com as Professoras corroboram resultados anteriores (LYRA; ASSIS; NJAINE; OLIVEIRA; PIRES, 2009), uma vez que somente as Professoras com sofrimento psíquico referiram problemas de depressão e ansiedade entre os alunos.

Santos (2006) relata que diante das adversidades que condicionam o sofrimento no trabalho, os professores criam estratégias de defesa ou de enfrentamento no sentido de buscar o mínimo equilíbrio frente ao exercício da docência. Lidar com comportamentos tidos "problemáticos" em sala de aula costuma não ser uma tarefa fácil. Embora as estratégias de mediação de conflitos com o próprio aluno tenha sido uma maneira positiva de lidar com esses comportamentos, há de se considerar o enorme desgaste mental dessas profissionais no exercício de sua profissão. Por sua vez, a ênfase dada pelas Professoras com SP à necessidade de encaminhar os alunos com problemas de comportamento para serviços especializados pode refletir um olhar sensível ao problema identificado e a visão de que o aluno necessita desse apoio especializado para lidar com determinada situação. Pode também, em alguns casos, representar uma tentativa de não lidar diretamente com esses problemas, repassando-o para outrem.

Conforme a análise de Dejours (1992) sobre a psicodinâmica do trabalho, os trabalhadores elaboram defesas individuais e coletivas para lutar contra o sofrimento, na medida em que esse não é localizável em um primeiro momento. Sabe-se que nem todos suportam as dificuldades existentes ou reagem da mesma maneira diante da possibilidade de sofrer e de adoecer. De acordo com as diferentes formas de utilizar a força de trabalho, que no caso dos Professores é principalmente feminina, e diante do fato de que a maioria dessas Professoras tem inúmeras jornadas no dia a dia, várias formas de sofrimento e desgaste, tanto físico quanto psíquico são encontradas.

A ausência de associação entre SP pelas Professoras e relacionamento Professor-aluno em sala de aula sugere que a presença de SP nas Professoras estudadas advém de fatores mais complexos que os vivenciados exclusivamente em sala de aula e que 
não estão relacionados diretamente com a convivência cotidiana com o aluno. O papel da direção escolar, a relação entre docentes e demais funcionários da escola, além das condições estruturais que possibilitam o funcionamento da escola e que delineiam as condições de magistério no país são também crucialmente importantes.

Outros fatores que contribuem para o desgaste mental e físico desses profissionais são: dar aula para um número grande de alunos em sala de aula, relatado por $50 \%$ das Professoras, trabalhar em mais de uma escola por semana $(47,2 \%)$ e sair de uma escola para outra sem descanso algum $(36,6 \%)$. Na busca por um salário que supra suas necessidades, o docente, muitas vezes, tem que trabalhar em inúmeras escolas durante a semana, sem ao menos ter tempo para descansar durante essas atividades. Neste sentido, a compreensão da profissão docente perpassa o próprio processo de proletarização da profissão, tendo em vista que a mulher sempre foi a principal referência na atividade docente e que o seu lugar na divisão sexual do trabalho sempre foi desvalorizado (KERGOAT, 1989; NOVAES, 1984).

A identificação de problemas de comportamento é condição básica para o bem-estar futuro da criança, mas por si só não traz efeitos benéficos se não possibilitar uma intervenção adequada. Muitos profissionais, apesar de identificarem sinais que indicam pistas para um possível problema de comportamento na criança, desconhecem a sua etiologia e muito menos os fatores que os desencadeiam. Por não dispor de meios ou condições para ajudá-los contribuem para desfechos negativos com relação ao futuro de alunos que apresentam de fato esses problemas. Uma das estratégias utilizadas é o encaminhamento que, se não for bem articulado e direcionado (já que a realidade dos recursos da rede pública para a resolução desses problemas é bastante precária) pode gerar um desencargo do profissional, sem quaisquer resoluções. Destaca-se que o encaminhamento deve ser utilizado em casos necessários, mas jamais isenta o profissional que lida com a criança de continuar atuando, dando-lhe a segurança e apoio necessários.

As condições ainda hoje precárias em muitos aspectos do ensino público no país, as condições de trabalho e de saúde do Professor, bem como a maneira como a escola reage frente aos alunos que apresentam dificuldades podem contribuir para um ciclo vicioso de violência.

Igualmente é necessário que haja apoio aos docentes, tão reivindicado especialmente pelas Professoras com sofrimento psíquico, para que se estabeleça na escola um ambiente seguro e saudável, tanto para o professor quanto para o aluno. $\mathrm{O}$ apoio aos docentes advém do estabelecimento de redes locais com outras estâncias que cuidam da proteção à infância, mas, principalmente, de uma boa gestão escolar que permita a construção de novas 
estratégias de mediação de conflitos e de boas relações entre os Professores, gestão acadêmica, alunos e pais (MINAYO; NJAINE; ASSIS, 2004).

\section{Referências}

ACHENBACH T. M, RESCORLA L. A. Manual for the ASEBA Schoolage forms \& profiles. Burlington, VT: University of Vermont, Research Center for Children, Youth \& Families; 2001.

AGRESTI A. Categorical data analysis. John Wiley \& Sons, 2002. ARAÚJO T. M., SILVANY NETO, A.M. Condições de trabalho e saúde dos professores da rede particular de ensino, SalvadorBA. Sindicato de Professores da Rede Particular do Estado de Bahia (SINPRO): Salvador. 1998.

ASSIS S. G. A violência familiar produzindo reversos. Problemas de comportamento em crianças escolares de São Gonçalo. Rio de Janeiro, 2007.

BARDIN L. Análise de conteúdo. Lisboa, Portugal: Edições 70, 1979.

$\mathrm{BEE}, \mathrm{H}$. A criança em desenvolvimento. Porto Alegre: Artmed, 1996.

BIRD, H. R. Epidemiology of childhood disorders in a cross-cultural context. Journal of child psychology and psychiatry, Elmsford, US, v. 37, n. 1, p. 35-49, 1996.

BOARINI , M.L; BORGES, R.F. Demanda infantil por serviços de saúde mental: Sinal de Crise. Estudos de Psicologia, Natal, v. 3, n. 1, p. 83-108, 1998.

BORDIN I. A. S; MARI J. J.; CAEIRO M. F. Validação da versão brasileira do Child Behavior Checklist (CBCL) (Inventário de comportamentos da Infância e Adolescência): dados preliminares. Revista ABP-APAL, São Paulo, v. 17, n. 2, 55-66, 1995.

Centro de Informações e Dados do Rio de Janeiro: Disponível em: <http://www.cide.rj.gov. br>. Acesso em 10 out. 2010.

CODO, W. Educação: carinho e trabalho. 4 ed. Petrópolis, RJ. 4a ed. Vozes, 2006.

COLL, C.; MIRAS, M. A representação mútua Professor / aluno e suas repercussões sobre o ensino e a aprendizagem. In: COLL, C; PALÁCIOS, J; MARCHESI, A. Desenvolvimento psicológico e educação. Porto Alegre: Artmed, 2001.

COUTINHO, E.S.F. Fatores sócio-demográficos e morbidade psiquiátrica menor: homogeneidade e heterogeneidade de efeitos. 1995.Tese(Doutorado em Saúde coletiva) - Universidade federal da Bahia: Salvador, 1995.

DEJOURS, C. A loucura do trabalho: estudo de psicopatologia do trabalho. São Paulo: Cortez - Oborê, 1992. 
DELCOR, N. S, ARAUJ O, T. M, REIS E. J. F. B, PORTO L.A, CARVALHO F.M, SILVA M.O. Condições de trabalho e saúde dos Professores da rede particular de ensino de Vitória da Conquista, Bahia, Brasil. Caderno de Saúde Pública, Rio de Janeiro, v. 20, n. 1, 187-96, 2004.

DEPARTAMENTO DE INFORMÁTICA DO SUS: Disponível em: <http://tabnet. datasus. gov.br/cgi/tabcgi.exe?sim/cnv/obtrj.def>.

Acesso em: 20 fev.2010.

FERDINAND, R. F.; VAN DER ENDE, J; VERHULST, F. C. ParentTeacher Disagreement Regarding Psychopathology in Children: A Risk Factor for Adverse Outcome? Acta Psychiatrica Scandinavica, London, v.115, Issue 1, p.48-55, 2007.

FLEITLICH-BILYK, B; GOODMAN, R. Prevalence of child and adolescent psychiatric disorders in Southeast Brazil. Journal of the American Academy of Child and Adolescent Psychiatry, Baltimore, v. 43, n. 6, p. 727-734, 2004.

GARCIA, J. Representações dos Professores sobre indisciplina escolar. Revista Educação, Santa Maria, RS, v. 34, n. 2, p. 311- 24, 2009. GASPARINI, S. M; BARRETO S. M.; ASSUNÇÃO A. A. O Professor, as condições de trabalho e os efeitos sobre sua saúde. Educação e Pesquisa, São Paulo, v. 31, n. 2, p. 189- 99, 2005.

GASPARINI, S.M; BARRETO, S.M; ASSUNÇÃO, A.A. Prevalência de transtornos mentais comuns em Professores da rede municipal de Belo Horizonte, Minas Gerais, Brasil. Caderno de Saúde Pública, Rio de Janeiro, v. 22, n. 12, p. 2679-691, 2006.

HARDING, TW. Mental Disorder in Primary Health Care: A Study of Their Frequency and Diagnosis in Four Developing Countries. Psychological Medicine, Cambridge, v. 10, issue 2, p. 231- 41. 1980.

JODELET, D. Representações sociais: um domínio em expansão. In: As Representações. Rio de Janeiro: EDUERJ. 2001.

JUNQUUEIRA, C; MULS, L. O processo de pauperização docente. Contemporaneidade e Educação, Salvador, v. 2, n. 2, p. 130-42. 1997.

KERGOAT, D. Da divisão do trabalho entre os sexos. Tempo social São Paulo, v. 1, v. 2, p. 88-96, 1989.

KOLKO, D.J.; KAZDIN, A.E. Emotional/behavioral problems in clinic and nonclinic children: correspondence among child, parent and teacher reports. J ournal of child Psychology Psychiatry, Oxford, v. 34, n. 6, p. 991-1006, 1993.

Lyra, G.F.D.; ASSIS, S.G.; NJAINE, K; OLIVEIRA, R.V.C. de; PIRES, T.O. A relação entre Professores com sofrimento psíquico e crianças escolares com problemas de comportamento. Ciência e Saúde Coletiva, Rio de Janeiro, v. 14, n. 2, p. 435-44, 2009. 
MARI, J.J.; WILLIAMS, P. A validity study of a psichiatric screening questionnaire (SRQ20) in primare care in the city of São Paulo. British J ournal of Psychiatry, London, v. 148, p. 23-26, 1986.

MARIANO, M. S. S.; MUNIZ, H. P. Trabalho docente e saúde: o caso dos Professores da segunda fase do ensino fundamental. Estudos e Pesquisas em Psicologia, Rio de Janeiro, v. 6, n. 1, p. 76-88, 2006.

MINAYO, M. C. S; NJAINE, K; ASSIS, S. G. Cuidar cuidando dos rumos: conversa com educadores sobre avaliação de programas sociais. Rio de Janeiro. FIOCRUZ/ ENSP; 2004.

MURRAY, C. J. L; LOPEZ, A.D; (Eds.). The global burden of disease. Geneva: World Health Organization; 1996.

NEVES, M. Y. R; SILVA, E. S. A dor e a delícia de ser (estar) Professora: trabalho docente e saúde mental. Estudos e Pesquisas em Psicologia, Rio de Janeiro, v. 6, n. 1, p. 63-74, 2006.

NOVAES, ME. Professora primária: mestra ou tia. São Paulo: Cortez, 1984.

PORTO, L. A.; CARVALHO, F.M; OLIVEIRA, N.F; NETO, A.M.S; ARAUJ O, T.M; REIS, E.J.F.B; DELCOR, N.S. Associação entre distúrbios psíquicos e aspectos psicossociais do trabalho de Professores. Revista de Saúde Pública, São Paulo, v. 40, n. 5, p. 818-26, 2006.

RANGEL, M. A representação social como perspectiva de estudo da escola. Tecnologia Educacional, Rio de Janeiro, v. 22, n. 112, p. 11-15, 1993.

RISTUM, M. O conceito de violência de Professoras do ensino fundamental. 2001. 410fls. Tese (doutorado em Educação) Universidade Federal da Bahia; Salvador (BA): FACED, 2001.

SCORTEGAGNA, P; LEVANDOWSKI, D. C. Análise dos encaminhamentos de crianças com queixa escolar da rede municipal de ensino de Caxias do Sul. Interações, São Paulo, v. 9, n. 18, p. 127-152, 2004.

SANTOS, G. B. As estratégias de fuga e enfrentamento frente às adversidades do trabalho docente. Estudos e Pesquisas em Psicologia, Rio de Janeiro, v. 6, n. 1, p. 128- 32, 2006.

SILVA, A.M.M. Educação e Violência: qual o papel da escola? Disponível em: <http://www.dhnet.org.br/educar/redeedh/bib/aidal.htm>. 1999. Acesso em 18 nov. 2010.

SILVA, A. T. B. Problemas de comportamento e comportamentos socialmente adequados: sua relação com as habilidades sociais educativas de pais. 2000. Dissertação (Mestrado em Educação especial) - Universidade Federal de São Carlos, São Carlos, São Paulo; 2000.

\section{Endereço para correspondência}


Gabriela Franco Dias Lyra, Simone Gonçalves de Assis,

Kathie Njaine, Thiago de Oliveira Pires

Sofrimento psíquico e trabalho docente - implicações na detecção de

problemas de comportamento em alunos

\section{Gabriela Franco Dias Lyra}

Av. Brasil, 4036 sala 700, CEP 21040-361, Manguinhos, Rio de Janeiro - RJ.

Endereço eletrônico: gabriela@fiocruz.br

\section{Simone Gonçalves de Assis}

Av. Brasil, 4036 sala 700, CEP 21040-361, Manguinhos, Rio de Janeiro - RJ.

Endereço eletrônico: simone@claves.fiocruz.br

\section{Kathie Njaine}

Av. Brasil, 4036 sala 700, CEP 21040-361, Manguinhos, Rio de Janeiro - RJ.

Endereço eletrônico: kathie@claves.fiocruz.br

\section{Thiago de Oliveira Pires}

Av. Brasil, 4036 sala 700, CEP 21040-361, Manguinhos, Rio de Janeiro - RJ.

Endereço eletrônico: claves@claves.fiocruz.br

Recebido em: 28/11/2011

Reformulado em: 17/04/2013

Aceito para publicação em: 21/04/2013

Acompanhamento do processo editorial: Deise Mancebo

\section{Notas}

* Pesquisadora Colaboradora do Centro Latino Americano de Estudos de Violência e Saúde J orge Careli - (CLAVES/ FIOCRUZ).

** Pesquisadora do Centro Latino Americano de Estudos de Violência e Saúde Jorge Careli - FIOCRUZ

*** Pesquisadora do Centro Latino Americano de Estudos de Violência e Saúde J orge Careli - FIOCRUZ.

****Estatístico do Centro Latino Americano de Estudos de Violência e Saúde Jorge Careli - FIOCRUZ. 